\title{
A prática do romance de Antonio da Fonseca Soares: o ms. 2998 BGUC
}

\author{
Luís Fernando Campos D'Arcadia \\ Universidade Estadual Paulista (UNESP), Assis, São Paulo, Brasil \\ luisfcdarcadia@gmail.com \\ https://orcid.org/0000-0002-0126-947X
}

DOI: http://dx.doi.org/10.21165/el.v47i2.1986

\begin{abstract}
Resumo
O manuscrito 2998 da sala de reservados da Biblioteca Geral da Universidade de Coimbra apresenta, em sua primeira página, a didascália "Romances Portugueses de Antonio d'Affonseca, q despois se chamou Fr. Antonio das Chagas". Dela pode-se constatar que o compilador dos textos estabelece um contraste entre duas figuras: o primeiro é o fidalgo Antônio da Fonseca Soares (1631-1682), Capitão de Cavalaria do exército português e uma das figuras mais notórias do conceptismo português, o segundo é esse mesmo autor depois de ser ordenado frei franciscano em 1663. Aqui, procura-se examinar, a partir do estudo de romances registrados nesse manuscrito, como o contraste exposto na didascália vai além da mera nomeação do autor, possuindo a função de estabelecer ao público daquele manuscrito uma série de expectativas para a leitura e interpretação dos textos nele contidos.
\end{abstract}

Palavras-chave: romance; Barroco; Filologia.

\section{The practice of the romance by Antonio da Fonseca Soares: ms. 2998 BGUC}

\begin{abstract}
The manuscript 2998 of the General Library of the University of Coimbra (BGUC) presents in its first page the caption "Romances Portugueses de Antonio d'Affonseca, q despois se chamou Fr. Antonio das Chagas". The compiler of the texts establishes a contrast between two figures: the first is Antonio da Fonseca Soares (1631-1682), who became a cavalry captain of the Portuguese army during the Restoration War and one of the most notorious authors of Portuguese conceptism, the second, the name he adopted after ordained as a Franciscan friar in 1663 . The intention here is to briefly examine how the title goes beyond the mere indication of authorship, it has the function of establishing to the sixteenth century reader a series of expectations for the reading and decoding of the texts contained in the manuscript.
\end{abstract}

Keywords: romance; Baroque; Philology.

\section{Antônio da Fonseca Soares e o romance}

Tratando-se de um autor e de uma obra distantes de nosso tempo em mais de 300 anos, ambos talvez mereçam alguns comentários no sentido de contextualização. Antônio da Fonseca Soares (1631-1682) é o nome laico pelo qual o frade franciscano Antônio das Chagas era conhecido antes de sua ordenação. É por esse nome sacro que interessados na literatura portuguesa do século XVII provavelmente o encontrarão nos compêndios e histórias da Literatura Portuguesa. Como frade, compôs obras de cunho religioso, com um vasto repertório epistolar, suas "Cartas Espirituais". A obra tida como "poesia vulgar", por sua vez, é raramente mencionada. Ainda, enquanto a obra do frade se 
encontra editada e estudada, a de sua persona vulgar é encontrada no mesmo estado manuscrito em que circulou no século XVII: em "livros de mão" compilados muitas vezes anonimamente e com pouco cuidado quanto à atribuição de autoria.

A esse caos manuscrito acrescenta-se o desdém crítico. Essa poesia conhecida como "vulgar" foi atacada pelo viés formal como frívola ou "excessivamente ornamentada", passando pelo rótulo de uma "degeneração estrangeira" durante o período neoclássico ou, mais recentemente, "derivativa". Uma censura moral também é frequente quanto à parte erótica ou pornográfica de sua produção.

O estudo da produção de romances pode mitigar algumas dessas lacunas. Como teóricos modernos que tratam do século XVII demonstram, há um universo de produção e recepção literárias diferente do que se tem na atualidade, em diversos aspectos. Essa diferença envolve tanto princípios retórico-poéticos quanto uma prática "editorial" que não compreende autoria, publicação e edição como se faz hoje.

O romance como forma poemática, definido em princípio como uma série de quadras composto de redondilhas menores, aceita uma variedade de temas e motivos mostrando-se narrativo, elegíaco, sacro, cômico, lírico, amoroso e até pornográfico. As origens dessas composições estão nas narrativas em verso escritas (ou declamadas) em línguas românicas, sendo essa diferenciação linguística o elemento em comum. Na tradição ibérica, a prática continuou com o fim da idade média, ficando conhecida na Espanha a dos romances nuevos,

[...] os romances dividiram em dois versos curtos o longo verso da gesta, isto é: os trovadores passaram a escrever separados os heptassílabos da gesta original; sucedeu daí que só os hemistíquios pares $\left(2^{\circ}, 4^{\circ}, 6^{\circ}\right.$, etc.) rimam entre si, ficando sem rima os hemistíquios ímpares. (SPINA, 2003, p. 190).

Nesse contexto, um exame da prática de Antônio da Fonseca Soares pode recuperar tanto a continuação de uma prática poética que deve à oralidade "popular", quanto como participante de uma tradição própria dos seiscentos. Essa tradição, como discutiremos, envolve uma compreensão idiossincrática da materialidade do texto e uma interpretação da noção clássica de decoro poético.

\section{Produção manuscrita e autoria}

O estudioso brasileiro Marcello Moreira, em sua obra Critica Textualis in Caelum Revocata?: uma proposta de edição e estudo da tradição de Gregório de Matos e Guerra, demonstra que compilações manuscritas, brasileiras e portuguesas, provenientes dos séculos XVII e XVIII são artefatos bibliográficos que não devem ser confundidos com livros modernos. Esse tipo de publicação, que o autor chama de publicação escribal, é fruto de relações sociais bastante diversas das nossas, pertencendo a "uma longa tradição ibérica de códices manuscritos" (MOREIRA, 2011, p. 295).

Esse ponto de vista, que foca em aspectos como a materialidade do texto e suas práticas de escrita e leitura, constitui uma continuidade de uma série de pesquisas iniciadas em meados do século XX que, como resume o estudioso João Adolfo Hansen (2011, p. 25), tem o objetivo de construir uma "nova história social da escrita" e possui a contribuição de teóricos como, entre muitos, Roger Chartier e Paul Zumthor. Além disso, incluem-se nessa linha "material" pesquisadores que gravitaram em torno de uma linha de estudos conhecida como New Philology, que deve bastante a estudiosos como Bernard 
Cerquiglini. Essa linha de pensamento (assim como a tese de Moreira a ela relacionada) tem como princípio central a "unidade indissociável dos códigos linguísticos e bibliográficos" (HANSEN, 2011, p. 20).

Como essa linha de pesquisa contribui para a compreensão do objeto de estudo proposto neste trabalho? O manuscrito 2998, preservado na sala de reservados da Biblioteca Geral da Universidade de Coimbra, inicia-se com a seguinte didascália: "Romances Portugueses de Antonio d'Affonseca, q despois se chamou Fr. Antonio das Chagas". Em seguida, apresenta uma lista dos poemas compilados em ordem alfabética do primeiro verso. Conforme o próprio Marcello Moreira indica como uma das teses centrais de seu trabalho, elementos paratextuais são uma parte essencial tanto para uma "reatualização do referencial histórico" (cf. MOREIRA, 2011, p. 157), quanto como "dispositivos retóricos que simulam as condições empíricas, concretas, de atualização textual" (MOREIRA, 2011, p. 157).

Pode-se constatar que a didascália, aplicada a todos os romances da coleção, configura o conjunto de poemas como uma unidade de sentido. O primeiro termo é a referência à forma/gênero: romance. Em seguida, indica a língua da seleção, português, em oposição a romances em espanhol também atribuídos a Fonseca em outros momentos. Em terceiro lugar, atribui a autoria dos poemas, que se apresenta dupla: Antonio d'Affonseca/Fr. Antonio das Chagas. Existe uma ênfase, no entanto, de que as obras são atribuídas ao primeiro, fazendo uma distinção por meio do "despois".

Para compreendermos melhor o que a didascália desse artefato manuscrito espera dos leitores, propomos examinar uma outra obra que utiliza a didascália de um modo diferente, porém igualmente indispensável para a compreensão do texto. A obra é um soneto atribuído a Antonio da Fonseca Soares que possui a didascália "Ao cavalo do Conde de Sabugal, que fazia grandes curvetas":

Galhardo bruto, teu bizarro alento Música é nova com que aos olhos cantas.

Pois na harmonia das cadências tantas

É clave o freio, é solfa o movimento.

Ao compasso da rédea, ao instrumento

Do chão, que tocas, quando a vista encantas

Já baixas grave e agudo já levantas,

Onde o pisar é som, e o andar é concento [sic]:

Cantam teus pés, e teu meneio pronto.

Nas fugas não, nas clausuras medido,

Mil consonâncias forma em cada ponto

Pois em salsas airosas suspendido

Ergues em cada quebro um contraponto,

Fazes em cada passo um sustenido. (HANSEN; PECORA, 2002, p. 164)

O poema, conforme Maria de Lourdes Belchior Pontes (1953), foi produzido provavelmente no ambiente da Academia dos Generosos, e é reproduzido de modo individual em várias coletâneas do período e posteriores. A didascália que o acompanha indica elementos práticos de produção: um soneto elaborado em uma situação circunstancial, ou seja, uma glosa de um tema ligado a um evento social empírico e individualizado no tempo. É apresentado o título nobiliárquico, sinal da representação do 
prestígio na sociedade de corte e a arte equestre é um elemento importante no evento social em questão - a virtuosidade na arte equestre era um signo de prestígio.

A partir da leitura do soneto, é possível identificar a estrutura engenhosa relacionada à poesia conceptista, a metáfora em enigma, para usar a terminologia de Aristóteles, que cria um conceito a partir de duas ideias radicalmente diferentes (música/curvetas praticadas no hipismo). O conceito é dado pelo oxímoro que inicia o poema ("Galhardo bruto"), que indica o contraste entre a elegância do adjetivo "galhardo", que se atribui a fidalgos, e o "bruto", do universo animal. Em seguida, recebemos uma proposta sinestética, "aos olhos cantas", o que culmina na descrição do cavalo (freio, rédea, meneio) em paralelo com o léxico da música (clave, solfa, compasso, instrumento). A arte equestre é posta em paralelo com a arte musical, apresentando uma visualidade que nos leva a acreditar que tanto o autor quanto o público a que esse poema foi primeiramente publicado, estiveram fisicamente presentes durante os exercícios do cavalo do conde. As referências estariam vivas e recentes aos leitores e expectadores do poema em sua primeira leitura/performance. Pela repercussão do poema no período, pode-se especular que ele foi reconhecido como um bom exercício de engenhosidade e de adequação ao decoro que se espera do soneto encomiástico. Tal engenhosidade é vinculada ao nome de Antonio da Fonseca Soares. Uma outra razão, no entanto, também é motivo de termos selecionado tal poema. Se sua virtuosidade em se adequar aos padrões esperados no século XVII deu grande destaque ao soneto, nos séculos posteriores esses mesmos motivos foram a razão de sua infâmia. Esse é o soneto escolhido por Luís Antônio Verney como o símbolo de um tipo de poesia que deveria ser substituída:

Dos espanhóis o aprenderam os Portugueses; e commumente se persuadem que quem subtiliza melhor e diz coisas menos verossímeis é melhor Poeta. Metáforas mui fora de propósito, encarecimentos inauditos, são os seus mimosos. Ouvi gabar muito um soneto do Chagas, feito a um cavalo do Conde de Sabugal, pela metáfora da Música [...]. Mas eu, considerando o tal epigrama acho que é uma total parvoíce, desde a primeira palavra até a última. Não acho nele conceito algum; as palavras são impróprias, e muitas não têm significação certa [...]. (VERNEY, 1950, p. 255-256).

O projeto iluminista de Verney propunha uma nova regulação para os mecanismos da verossimilhança poética que recuperam a mediocridade áurea horaciana, que une o "doce ao útil", com as funções poéticas de ensinar e deleitar. Uma poesia que se utiliza do enigma e enfatiza o deleite e a maravilha não é mais bem-vinda. Verney (1950, p. 265) se recusa a "entrar na brincadeira" e não tenta resolver o enigma:

A regra que eu observo neste particular é esta: quando vejo um Poeta destes, que se serve de expressões que nada significam, ou que compõem de sorte que o não entendem, assento que não quis ser entendido, e em tal caso, procuro fazer-lhe a vontade, e não o leio.

Portanto, a partir do destaque que Verney dá a uma obra que ele "ouvira gabar", ou seja, era reconhecida dentro da cultura letrada da qual o intelectual compartilhava, pode-se presumir que a atribuição a Antonio da Fonseca Soares evocava autoridade na prática engenhosa conceptista.

Retornando à didascália presente no manuscrito 2998, um segundo nome, então, é apresentado: "q depois se chamou Fr. Antonio das Chagas". Em 1663, Antonio da Fonseca Soares se torna frei franciscano, adotando o nome de Antonio das Chagas. Com 
esse nome, destacou-se como orador, sendo comentado por Antonio Vieira que critica a teatralidade exacerbada de Frei Antonio das Chagas e dos sermões franciscanos (cf. CHAGAS, 1957, p. XXI). Sob esse nome produziu uma epistolografia, durante 11 anos de peregrinações apostólicas, dando origem à obra Cartas Espirituais, sua primeira obra impressa, que conheceu diversas edições desde 1684. O Frei ainda escreve obras devocionais, depois reunidas com o título Desengano do Mundo, publicadas em 1743.

Há nessa didascália uma clara dicotomia, que pode ser desenvolvida em duas personas poéticas relacionadas à mesma entidade autoral. $\mathrm{O}$ adjetivo "despois" é também um sinal claro de que os poemas que se seguem se referem somente à primeira. A ideia da auctoritas, autoridade, também é relevante. Como muitas vezes esse reconhecimento acontecia até depois da morte do autor, sobre um material apócrifo, exemplos da "melhor" poesia eram automaticamente atribuídos a uma autoridade. Por exemplo, a melhor sátira, atribuída a Gregório de Matos, e o melhor romance conceptista, atribuído a um autor como Antônio da Fonseca Soares. Nesse contexto, as alcunhas são evidência de uma relação íntima entre gênero e autor: Gregório de Matos, no Brasil, era conhecido como o "Boca do Inferno", e Antônio da Fonseca Soares, em Portugal, era conhecido como "Capitão Bonina".

João Adolfo Hansen, em seu livro A sátira e o engenho, enfatiza a importância de fazer uma leitura retórica-poética dos próprios dados biográficos apresentados nas "Vidas" dos autores (em si um gênero narrativo). A Gregório de Matos foi atribuída a caracterização do satírico, que, na interpretação aristotélica, "ria ferindo". Sua "viola", mais do que um instrumento musical, era uma representação da elocutio baixa satírica. Em oposição ao cômico, a sátira era classificada como "riso com dor", um gênero misto ("monstro") que fazia uso da elocutio baixa e inventio cômica com o fim elevado de corrigir a moral, procurando manter a saúde do corpo místico do estado teocrático católico. Daí a representação de Gregório de Matos como uma figura indecente e intempestiva. A metonímia "Boca" indica sua monstruosidade, humanizando o órgão que toma vida própria independentemente do corpo.

Já no caso de Antônio da Fonseca Soares, sua alcunha era a de Capitão Bonina, que reúne dois aspectos pelos quais o autor ficou conhecido: sua obra "vulgar", porém aguda, em romances eróticos e cômicos e sua obra mais "elevada". A parcela elevada, reservada ao "Capitão", está relacionada ao seu serviço ao reino como Capitão de Cavalaria do Terço de Évora durante a Restauração Portuguesa (1640-1668), compondo os épicos em oitavas camonianas que narram eventos daquele conflito, Elvas Socorrida e Mourão Restaurado. A parte chã da obra, as "Boninas", representariam os estilos baixo e mediano da lírica erótica, cômica e satírica, praticada nas redondilhas maiores e menores do romance. Um evento biográfico serve à caracterização desse aspecto de sua personalidade literária: antes de terminar seus estudos na Universidade de Évora, Antônio da Fonseca, por razões amorosas, mata um rival em duelo, fugindo imediatamente para o Brasil e, em seguida, procura no serviço militar a absolvição pelo crime.

Os estilos de Fonseca podem ser relacionados ao ordenamento retórico-poético de tradições como a da Roda de Virgílio, justificando o lugar de autoridade nesse contexto. Conforme aponta Ivan Teixeira em seu Mecenato pombalino e poesia neoclássica, considerando as três obras fundamentais do autor romano, temos a Eneida, de estilo elevado e relacionada à função retórica do movere (comover), as Geórgicas, o estilo mediano relacionado à função retórica do docere (ensinar), e, por fim, as Bucólicas, de 
estilo baixo e ligada à função do deleite (delectare). $\mathrm{O}$ autor então sintetiza uma leitura de Curtius sobre a tradição medieval de poesia:

Segundo Curtius, a retórica medieval distingue três espécies de estilo, às quais se associam determinadas classes de pessoas, algumas árvores e alguns animais. Essa divisão baseia-se nas obras de Virgílio: o estilo humilde (Bucólicas, pastor, faia), o estilo medíocre (Geórgicas, agricultor, árvores frutíferas) e o estilo grave (Eneida, guerreiro e cedro). (TEIXEIRA, 1999, p. 383).

Teixeira então menciona a segunda categoria como justificativa retórico-poética para a poesia encomiástica, a qual une as funções de deleitar e educar. A alcunha "Capitão Bonina", portanto, reconhece a autoridade de Fonseca em pelo menos dois pontos desse sistema: os gêneros elevados e os gêneros baixos.

As obras épicas, após sua morte, receberam uma edição nas coletâneas Fênix Renascida e no Postilhão de Apolo. Quanto aos poemas considerados baixos, no entanto, sua circulação, como era o usual na época, se dava por folhas avulsas entre os poucos letrados ou, também muito provável, de maneira oral.

\section{Dois exemplos da prática do romance}

O manuscrito 2998 possui um corpus selecionado principalmente pelo gênero poético do romance. Essa noção de gênero reúne tanto elementos formais e temáticos, que, no século XVII, eram elementos inseparáveis, não podendo ser diferenciados em uma dicotomia. Essa prática era definida pela produção e recepção, que de modo coletivo criava tradições, autoridades e princípios de composição a serem emulados.

Em um paralelo à "movência" dos textos medievais estudados por Paul Zumthor, o manuscrito 2998 apresenta, em suas transcrições, a "variância" inerente à cultura manuscrita dos seiscentos. Um exame desse pequeno corpus em sua materialidade já evidencia uma "incerteza" na lição manuscrita dos poemas: 4 poemas dos 20 primeiros poemas apresentam algum "erro" relacionado à transcrição. Os romances 11, 18 e 20 possuem estrofes retiradas (rasuradas pelo escriba). Esses "erros" evidenciam a fluidez inerente à materialidade do texto, cuja lição, mais do que centrada em uma "vontade autoral", pode estar relacionada a elementos do gênero ou da forma poética, ditados, ao mesmo tempo, pela tradição e por preceptistas desde a antiguidade até aos tempos de Fonseca.

A ocasião mais peculiar é a do romance $18^{1}$, cuja última estrofe é retirada, e a penúltima reduzida a um dístico:

\footnotetext{
${ }^{1}$ Critérios para a transcrição interpretativa do ms. 2998 BGUC: manutenção da pontuação; manutenção de sinais diacríticos; desenvolvimento de abreviações, com a termo extrapolado marcado por itálico (ex.: que); trechos com problemas de compreensão mantidos entre colchetes ([]); separação vocabular uniformizada segundo o sistema atual.
} 
Romançe 18

Buscando huma noutte destas da cama obrando socego e o tributo do descuido pagando esse torpe imperio

Quando se me reprezenta no sonho mais Lizonjeiro vossa beleza a quem disse muy semelhantes

requebros.

Anday câ minha menina falai comigo hú pequeno respondei me aõ que vos

digo,

concendei me o que uos

pesso.

Que he isto amores! deixai me! isto meu bem uos mereço? tamanho aggrauo he buscar uos,!

tanta culpa foi querer vos! Inda profiais em ir uos

Sois teimoza por extremo, nao vos abranda o que

sinto!

naõ vos Lastima o que

peno!

Que fogis meos amorinhos! que fazeis meu doçe emprego!

naõ uos vejo, que martirio! naõ uos falo que tromento

Vos mal comigo; he tal cazo assim paguais meos extremos!

se uos busco com retiros, se vos falo com silençios

Gostais de queimar me o sangue dizei fermoza he bem feito serem os meos sacraficios imanas vossos desprezos

Jezus ! naõ sey como sois certo que tendes naõ preço carinhos quando ingrata aos meos

incendios

quando tibia aos meos

Rides de ouvir me! oh valhaca gostais ver me remoendo olhay que as deficuldades a vivão mais os dezejos Deytai vos áqui comigo
Vosso ayo ser pertendo as maos, e a boa vontade por uos minha alma

prometo

Destoucay essa toalha os aufenetes desprego posto sem nuvem me abrazem os rayos desse cabello

Despi o habito meu bem minha menina por certo não ha mais garboza dama do que vos ficais em fresco

Naõ fugais esse colete ajudar a despir quero vedados bem sey são pomos

Desse paraizo os peitos.

Saya, guarda pe , e a nagoa Tiray mançinho; pois temo Que afino dessa çintura Quebre qualquer movimento

As mejas dessas colunas quero tirar: mas recejo. Por serem neve coalhada se vaõ nas maos derretendo Mostray ca os pes! que he isto meos amores nada vejo deve ser que nos meos

olhos tenho posto estes argueiros.

Despi; tambem a camiza, coitadinha estais tremendo tiray as maos que escondeis athe de mim tendes pejo.

Deitay uos aqui comigo andai depressa pois quero ver este leito huma ves do Sol cristalino berço,

Hora chegai para ca, que inda estais longe de perto

deixai me que amante abelha

Libeo nacar desses beiços

Comunicai vos comigo e os mais intimos segredos receba do centro dalma hum alento douto alento

Enlaçay braços com braços chegai a meu peito, o peito vejao se huá ves mescladas 
incendios.

as tibiezas com os

Dais ays ; isto nao foi nada, fugis; de que tendes medo, ja o pejor he paççado essas invenções deixemos;

Ameaçais me que he isto eu nem zombando ver quero

que seja meu sendicante de prata esse uosso dedo.

Quedo eis vos; isso he melindre, quereis sarar, pois eu crejo na repetiçaõ do damno haveis de achar o remedio .
Va outra ves meos amorres, perca se ja os reçejo que em mar deleite trocado vereis esse mar vermelho

Sois bonita; chegai mais [ora sus] naõ estais ageito A sim mima \%

edizas [ ] [ ? a ${ }^{2}$ (Ms. 2998, fólios 26-28)

O romance, evidentemente, possui uma natureza abertamente erótica e a menção do hábito indica sua inserção na temática comum no período do amor freirático. A engenhosidade conceptista da metáfora, de acordo com o que pede o gênero baixo e o deleite, aparece na forma de metáforas cristalizadas descritivas, ilustradas nos excertos abaixo:

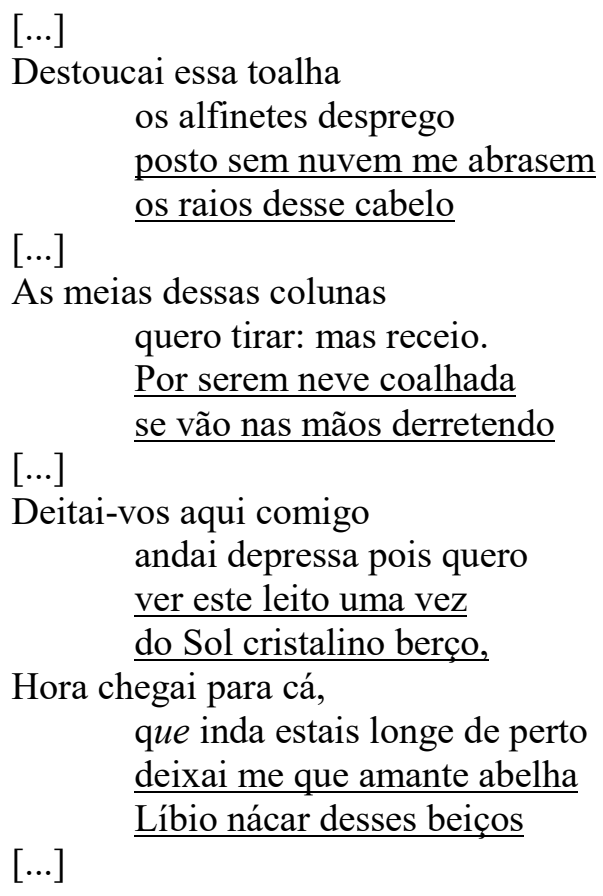

Para um leitor afastado do século XVII, o uso de uma estrutura complexa como a metáfora conceptista em conjunto com uma temática baixa ou até pornográfica pode constituir uma incoerência. Ao pensarmos no decoro retórico-poético da época, no entanto, como o oferecido por tradições como a roda de Virgílio (mencionada anteriormente), a construção da coerência obedece a numa tradição construída

\footnotetext{
2 Trecho riscado na fonte manuscrita.
} 
coletivamente. $\mathrm{O}$ romance, portanto, se mostra como um gênero que aceita uma matéria baixa e uma forma elevada.

Quanto à estrutura das estrofes, dos 20 poemas, nove apresentam alguma irregularidade diante da forma mais tradicional de estrofes de quatro versos heptassílabos. Em três casos, a variação ocorre no fecho do poema (romances 1, 2, 13 e 15), em que a última estrofe é escrita como um dístico, cinco versos ou em redondilhas menores. Outros quatro apresentam uma estrofe irregular no meio do romance, que varia de três a cinco versos, geralmente contendo um esquema de rimas próprio. Um romance se destaca por conter um metro diferente, de seis sílabas poéticas (romance 5):

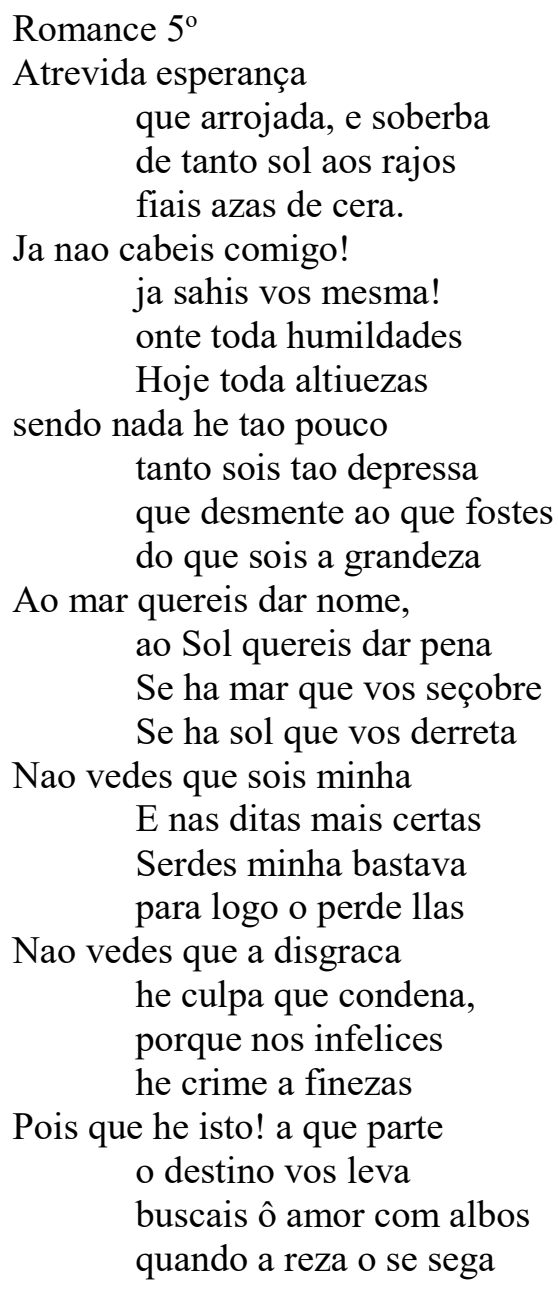

Romance $5^{\circ}$

Atrevida esperança que arrojada, e soberba de tanto sol aos rajos fiais azas de cera.

Ja nao cabeis comigo! ja sahis vos mesma! onte toda humildades Hoje toda altiuezas

sendo nada he tao pouco tanto sois tao depressa que desmente ao que fostes do que sois a grandeza

Ao mar quereis dar nome, ao Sol quereis dar pena Se ha mar que vos seçobre Se ha sol que vos derreta

Nao vedes que sois minha E nas ditas mais certas Serdes minha bastava para logo o perde llas

Nao vedes que a disgraca he culpa que condena, porque nos infelices he crime a finezas

Pois que he isto! a que parte o destino vos leva buscais ô amor com albos quando a reza o se sega

\author{
Oh naõ creais hum gosto, \\ que Embebida Em \\ quimeras \\ Mais vos mata com isso \\ com que muj vos enLeua!
}

Detende o uoö altiuo, porque em taõ alta esphera ou morreis de louca ou cahireis de nescia

Deixay que Leve o vento essas vans Lavaredas que ao mar saõ Luz sem

azas, e a Luz vento com ellas,

$\mathrm{Naõ} \mathrm{vos} \mathrm{fieis} \mathrm{das} \mathrm{chamas}$ que essa vontade aseza donde por boa nova tereis ser berboleta

Olhay que he mais que engano crer que tem vossa Estrella aspectos de benigna entre Enfluxos de aduerssa

Nao prozumais que Sorte vos deu tal pe que queira que em nao ter maõ nas

furias percais o pée com ella Paray que naõ se diga Que a fe é de huma firmeza mais que amar por respeitos quer ja morrer por teima

(ms. 2998, fólios 6-9)

Esse romance, por sua vez, apresenta uma temática mais elevada, mais coerente com o verso heroico quebrado. A interlocutora aqui, no lugar de uma dama, é a entidade abstrata "esperança", sendo que a propositio do poema, na primeira estrofe, possui a alusão erudita ao mito de Ícaro, que o poeta glosa nas estrofes seguintes. Com um tom mais elegíaco, este poema é também evidência da flexibilidade do romance como gênero. Um aspecto comum entre os dois poemas é o uso de quiasmos e trocadilhos. Esses ornamentos na elocução constroem a musicalidade do texto e engenhosidade de ideias, 
recuperando a oralidade do gênero com aliterações e assonâncias, servindo ao jogo engenhoso de conceitos.

\section{Poesia "vulgar", elocução erudita}

Espera-se que o exame desses dois poemas e os comentários a respeito da atribuição da autoria na didascália tenham exposto um aspecto importante das práticas de escrita no século XVII.

A questão da autoria é centrada mais na entidade autoral como uma construção retórico-poética, e menos na "vontade autoral", sendo ela uma manifestação de uma coletividade e tradição de gênero. Deve-se esperar, portanto, certo "caos" no que diz respeito à atribuição e transmissão dos poemas.

O esforço de dissertar a respeito da natureza baixa ou mediana dos poemas, contextualizando a produção literária conforme princípios de composição em voga no século XVII, faz entender que, mesmo os poemas sendo apócrifos, a persona a que são atribuídos apresenta uma coerência com o decoro proposto.

\section{REFERÊNCIAS}

CHAGAS, A. Cartas Espirituais. Selecção, prefácio e notas pelo prof. M. Rodrigues Lapa. Lisboa: Livraria Sá da Costa, 1957.

HANSEN, J. A. Códigos bibliográficos, escribas, manuscritura e códices da poesia atribuída a Gregório de Matos e Guerra. In: MOREIRA, M. Critica Textualis in Caelum revocata?: uma proposta de edição e estudo da tradição de Gregório de Matos e Guerra. São Paulo: EdUSP, 2011. p. 13-41.

HANSEN, J. A.; PECORA, A. (Org.). Poesia seiscentista: Fênix renascida e postilhão de Apolo. São Paulo: Hedra, 2002.

MOREIRA, M. Critica Textualis in Caelum revocata?: uma proposta de edição e estudo da tradição de Gregório de Matos e Guerra. São Paulo: EdUSP, 2011.

Ms. 2998 da sala de reservados da Biblioteca Geral da Universidade de Coimbra.

PONTES, M. L. B. Frei Antônio das Chagas: um homem e um estilo do século XVII. Lisboa: Centro de Estudos Filológicos, 1953.

TEIXEIRA, I. Mecenato pombalino e poesia neoclássica: Basílio da Gama e a poética do encômio. São Paulo: FAPESP; EDUSP, 1999.

SPINA, S. Manual de versificação românica medieval. São Paulo: Ateliê Editorial, 2003.

VERNEY, L. A. Verdadeiro Método de estudar. Lisboa: Sá da Costa, 1950.

Recebido em: 21/09/2017

Aprovado em: 06/11/2017 